\title{
Universidad y Salud
}

\section{SECCIÓN ARTÍCULOS DE REFLEXIÓN NO DERIVADOS DE INVESTIGACIÓN}

\section{La inaceptable exclusión de género del principio pro homine en salud y las subreglas de su aplicación}

\author{
Unacceptable gender discrimination of the pro homine principle in health and the sub-rules of its application
}

Isabel Goyes-Moreno', Mónica Hidalgo-Oviedo²

1 Doctora en Educación RUDECOLOMBIA. Docente Tiempo Completo. Directora grupo de investigación Derecho, Justicia y Región de la Universidad de Nariño. Pasto, Colombia.e-mail: igoyes@udenar.edu.co

2 Estudiante de Maestría en Derecho Laboral y Seguridad Social. Docente Hora Cátedra e Integrante grupo de investigación Derecho, Justicia y Región de la Universidad de Nariño. Pasto, Colombia. e-mail: monicahidalgoviedo@hotmail.com

\begin{abstract}
Resumen
La obligación de garantizar la equidad de género no es un asunto exclusivamente jurídico. Por el contrario, se trata de una necesidad social que le compete a todas las disciplinas. Las Ciencias de la Salud y el Derecho deben comprender y comprometerse con dicho mandato así uno de los principios (pro homine) de la nueva Ley Estatutaria de la Salud sea patriarcal, en tanto mantiene el lenguaje que otorga predominio a lo masculino sobre lo femenino. La novedad e importancia de este artículo radica en la reflexión sobre el carácter orientador que la mencionada Ley está llamada a cumplir en los próximos años y en los compromisos internacionales del Estado colombiano con la equidad de género. Sólo la comprensión general de que por principio "pro homine" debe entenderse como principio "pro persona", evitará mantener factores discriminatorios en un sistema de salud en el que aún persisten exclusiones y que con las subreglas jurisprudenciales permitirá una aplicación a favor del derecho a la salud de todas las personas.
\end{abstract}

Palabras clave: Pro homine, principio, salud, género. (Fuente: DeCS, Bireme).

\begin{abstract}
The obligation to ensure gender equality is not a merely legal issue. On the contrary, it is a social need that is the responsibility of all disciplines. The health sciences and law need to understand and engage with such a mandate, so one of the new statutory law of health principles (pro homine) is patriarchal, as long as it maintains a male language over the feminine one. The novelty and importance of this article lies in the reflection on the guiding character that the mentioned law is called to meet in the coming years and in the international commitments of the Colombian State with gender equality. Only the general understanding that the principle "pro homine", which should be understood as the principle "pro person", will prevent discriminatory factors in a health system in which there are still exclusions, and with the help of the jurisprudence sub-rules, it will enable an application in favor of the right to health of all people.
\end{abstract}

Keywords: Pro homine, principle, healt, gender. (Source: DeCS, Bireme). 


\section{Introducción}

La Ley Estatutaria de Salud fue declarada exequible mediante la Sentencia de la Corte Constitucional, C-313 de 2014. ${ }_{1}$ Se recurrió a una ley de este tipo por tratarse de un derecho fundamental cuya vulneración compromete la responsabilidad de todos los involucrados. En el artículo 6 de la Ley 1751 de 2015, se hizo referencia a los elementos y principios de la salud; listado que conjuga 18 rótulos de manera poco técnica en tanto no diferencia los principios de los elementos esenciales de este derecho y servicio público. ${ }_{2}$

Uno de los principios enunciados es el denominado "pro homine", el cual resulta atractivo por su carácter progresista dado que su uso deviene de la jurisprudencia internacional para solucionar conflictos relativos a derechos humanos. De conformidad con este principio, las decisiones deben favorecer el ejercicio del derecho antes que restringirlo. Por ello su vinculación con el derecho a la salud es altamente positivo, pues a diario deben desatarse controversias sobre los estándares más altos en materia de salud.

Sin embargo, un acercamiento crítico al significado simbólico del principio "pro homine" plantea los siguientes interrogantes: i) ¿El nomen "pro homine" conlleva discriminación de género?, ii) ¿Cómo han aplicado el principio pro homine los actores del sistema y cuál es el alcance de su competencia y autonomía interpretativa? y iii) ¿Qué subreglas de la jurisprudencia constitucional garantizan la interpretación conforme al principio pro persona en salud?

No es posible que la potencialidad del principio pro persona según Salvioli, ${ }_{3}$ a través del regresivo apelativo que la Ley Estatutaria contiene como pro homine, impida el uso del mismo a favor de la dignidad del titular del derecho a la salud, de la eliminación de todo tipo de exclusiones y de la inserción de los avances científicos en la prestación del servicio a la salud. ${ }_{4}$ Pese a los detractores de este postulado por lo finito de los recursos económicos, la legitimidad de su aplicación se impone ante la indefensión que la pérdida de la salud le acarrea al ser humano.
Existe una abundante literatura sobre temas de equidad de género y no discriminación, siendo Ariza, una de las más destacadas, en cuanto asume desde una perspectiva histórica el sentido real y simbólico de la subordinación femenina, así mismo, en torno al uso del principio pro homine como criterio de interpretación de normas internacionales de derechos humanos, debe mencionarse a Mepham. Sin embargo, según Cortés, ${ }_{8}$ la conexidad que hoy impone la Ley Estatutaria entre el principio pro homine, el derecho fundamental a la salud y la equidad de género comienza apenas en Colombia a trabajarse y sin duda, vendrán importantes estudios e investigaciones transdisciplinarias que dinamizarán sus interrelaciones.

\section{Materiales y métodos}

Para dar respuesta a las preguntas antes planteadas se realizó una selección de sentencias proferidas por la Corte Constitucional relativas al tema de salud, en el último decenio. Tales fallos se organizaron de manera cronológica para permitir una hermenéutica jurisprudencial con enfoque crítico y extraer aquellos principios que fueron base de la decisión. Ahora bien, la construcción de la línea de pensamiento judicial con sus avances y retrocesos se sustentó inicialmente en la categoría "pro homine" y luego, dio origen a escenarios fácticos que involucraban necesidades de salud de mujeres, tratamientos estéticos y grupos vulnerables, los que se relacionaron por tener unas mismas causales de rechazo del servicio.. El análisis jurisprudencial permitió extraer aquellos criterios fácticos, jurídicos, filosóficos y políticos que deben evidenciarse para lograr el éxito de la reclamación respectiva, esto es lo que se denomina en el lenguaje jurídico subreglas constitucionales. Estas conexiones condujeron a los resultados que se dan a conocer a continuación.

\section{I) ¿El nomen "pro homine" conlleva discriminación de género?}

El principio universal de igualdad fue consagrado en 1789 en la Revolución Francesa y ratificado posteriormente y con carácter integral en la Declaración Universal de los Derechos Humanos. ${ }_{10}$ No obstante, la persistente discriminación fundada en el sexo u orientación sexual dio lugar a instrumentos internacionales específicos como la Convención sobre la Eliminación de todas las Formas 
de Discriminación Contra la Mujer (CEDAW), ${ }_{11}$ que considera como discriminación en el artículo 1o “toda distinción, exclusión a restricción basada en el sexo que tenga por objeto o por resultado menoscabar o anular el reconocimiento, goce o ejercicio por la mujer, independientemente de su estado civil, sobre la base de la igualdad del hombre y la mujer, de los derechos humanos y las libertades fundamentales en las esferas política, económica, social, cultural y civil o en cualquier otra esfera". Y en materia de población LGTB desde el 2012, la Oficina del Alto Comisionado para los Derechos Humanos lanzó la campaña "Free and Equal" (Libres e Iguales).

"Esta iniciativa está completamente focalizada en visibilizar las violaciones y discriminación en contra de la comunidad LGTB a través de material pedagógico y un seguimiento permanente de la actualidad global en torno al tema". ${ }_{12}$

La Constitución de 1991, en concordancia con estas disposiciones internacionales, consagró en el artículo 13 el derecho a la igualdad y no discriminación en general. Y en el artículo 43, la igualdad de oportunidades entre hombres y mujeres. Tal contexto normativo concita la verificación del carácter discriminatorio del principio pro homine consagrado en la Ley Estatutaria.

Desde la Sentencia T-570 de 2013 de la Corte

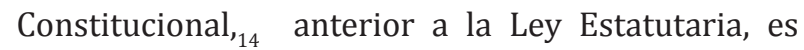
posible aludir al carácter excluyente del nomen "pro homine" y replantearlo como principio pro persona como lo enseña la doctrina mejicana. ${ }_{15}$

Esto por cuanto un tema femenino como la práctica quirúrgica de "mamoplastia reductora + pexia mamaria bilateral" prescrita por un cirujano plástico a quien padecía dolencias que ameritaban ser corregidas, se solucionó a favor de la mujer con apego al principio pro homine, en el entendido de que esta denominación es aplicable a hombres y mujeres, olvidando la Corporación la Sentencia C-804 de 2006, ${ }_{16}$ en virtud de la cual, declaró inexequible el término "hombre" para hacer referencia a personas de diferente sexo y recomendó en su lugar utilizar palabras como persona, ser humano, entre otras, más incluyentes. Lo que implicaba desde ese momento la adopción del principio pro persona tal como se utiliza a nivel internacional.
Esta incongruencia se reprodujo en la Ley 1751 de $2015,_{2}$ como principio según el cual todos los ciudadanos (como autoridades o actores del sistema de salud) cuando deban interpretar las normas vigentes, porque tienen vacíos, ambigüedades o en otras hipótesis, se inclinen por la menos restrictiva a la protección del derecho a la salud.

Es decir, que sin importar el género del destinatario de la interpretación normativa se debe buscar la defensa del derecho fundamental. Por tanto, para que el principio sea incluyente debe atenderse como principio "pro persona" o nominarse según el receptor o receptores de la interpretación: pro homine, pro femine, pro infans. Aunque este apelativo también excluye a un usuario frecuente del sistema de salud como lo es la población LGBTI, cuyos derechos son lesionados con la obstaculización del servicio o actos de discriminación aberrantes.

El artículo 29 de la Convención Americana de Derechos Humanos $_{17}$ contiene una disposición genérica, a partir de la cual, se sustenta el origen del principio "pro homine". Sin embargo, de su contenido puede afirmarse que el mismo es incluyente y que la denominación sexista, fluye de concepciones patriarcales conscientes o inconscientes. El texto en mención dice:

“1. Ninguna disposición del presente Pacto podrá ser interpretada en el sentido de conceder derecho alguno a un Estado, grupo o individuo para emprender actividades o realizar actos encaminados a la destrucción de cualquiera de los derechos y libertades desconocidos en el Pacto o a su limitación en mayor medida que la prevista en él. 2. No podrá admitirse restricción o menoscabo de ninguno de los derechos humanos fundamentales (...), so pretexto de que el presente Pacto no los reconoce o los reconoce en menor grado".

De igual manera, la Corte Interamericana de Derechos Humanos $_{18}$ independizó el objetivo perseguido con el principio, cual es la defensa del derecho en ciernes, del sujeto beneficiario. Así señaló la CIDH que: "entre varias opciones para alcanzar ese objetivo debe escogerse aquella que restrinja en menor escala el derecho protegido. Es decir, la restricción debe ser proporcionada al interés que la justifica y ajustarse estrechamente al logro de ese legítimo objetivo". 
Para Aguirre, ${ }_{19}$ "el principio pro persona es un principio general del sistema interamericano que debe obligar a los órganos del sistema interamericano, y a todos los órganos de aplicación del derecho internacional de los derechos humanos. El sistema existe para los derechos de las personas y no en contra de ellas".

Por tanto, la Ley estautaria de la salud acoge una denominación excluyente al nominarlo como "principio pro homine" separándose de la jurisprudencia de la Corte IDH y de las orientaciones de tratadistas expertos en la Convención, quienes hacen referencia al principio pro persona, incluyente y no discriminatorio.

Ahora bien, tal denominación fue utilizada por el

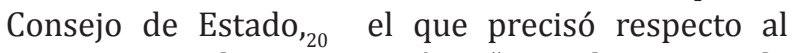
principio pro homine que éste "no milita contra la justicia, sino concurre a que la haya" lo que conlleva a que "entre varias opciones para alcanzar ese objetivo debe escogerse aquella que restrinja en menor escala el derecho protegido".

Por tanto, la Corte Constitucional en la Sentencia T-570 de 2013, ${ }_{14}$ actuó de manera acertada, privilegiando el derecho a la salud de la mujer, ya que se comprobó científicamente que la cirugía tenía fines funcionales y por lo tanto, la interpretación que condujo a su rechazo contenía una restricción inadmisible del derecho a la salud. Expresó la Corporación: "En este orden ideas, sin importar el cambio de regulación, el carácter funcional o reconstructivo de una cirugía plástica continúa siendo el criterio para determinar su inclusión en el POS, y solo el carácter estético o cosmético, un criterio de exclusión".

No obstante, la Corte reafirma el principio bajo el nomen "pro homine" sin tener en cuenta que la actora es una mujer y que bien pudo, hacer referencia al principio como "pro femine" o mejor aún, como "pro persona".

\section{Dijo la Corte:}

"Para determinar si un servicio médico está o no incluido dentro del plan de beneficios, (...) debe "aplicarse la interpretación que resulte más favorable a la protección de los derechos de la persona, de conformidad con el principio pro homine", es decir, la que permite a una persona alcanzar el máximo nivel de disfrute del derecho a la salud".

Se lamenta que en dicha oportunidad, pudiendo hacer pedagogía constitucional hacia la equidad de género, la Corte mantuvo un léxico sexista y en contravía del estándar internacional contenido en la Observación 14 del Comité de Derechos Económicos Sociales y Culturales ${ }_{21}$ que impone considerar "las diferencias basadas en la perspectiva de género", la que tomó como referente para hacer un control de constitucionalidad en sentido estricto de la Ley Estatutaria en la Sentencia C-313 de 2014. 1

De la Sentencia C-570 de 2013, ${ }_{14}$ fluye la aceptación del principio pro homine, obviando cualquier referencia a la discriminación que su denominación conlleva, buscando en su aplicación, que dicho principio abarque tanto a hombres como a mujeres cuando de proteger el derecho a la salud se trate. Esto ratifica la fuerza del lenguaje sexista y la dificultad de sustituirlo por uno incluyente que permite visibilizar la histórica discriminación.

\section{II) ¿Cómo han aplicado el principio pro homine los actores del sistema y cuál es el alcance de su competencia y autonomía interpretativa?}

Para Castaño, ${ }_{22}$ dado que el principio pro homine o pro persona adquiere relevancia frente a situaciones conflictivas en materia de salud que conciernen al paciente y su familia, al prestador del servicio, a la EPS y a los órganos de vigilancia y control, es preciso verificar las razones de concesión o negación de un servicio, sí en las mismas subyacen prejuicios derivados del sexo o diversidad sexual y el margen de autonomía y competencia de que dispone cada actor.

Ahora bien, la aspiración con la ley estautaria de la salud $_{,_{2}}$ es la eliminación de los obstáculos para el acceso a la prestación de los servicios de salud, tal como lo consagra el artículo 14 que expresa:

"Artículo 14. Prohibición de la negación de prestación de servicios. Para acceder a servicios y tecnologías de salud no se requerirá ningún tipo de autorización administrativa entre el prestador de servicios y la entidad que cumpla la función de gestión de servicios de salud cuando se trate de atención de urgencia. (...) Parágrafo 1. En los casos de negación de los servicios 
que comprenden el derecho fundamental a la salud con independencia a sus circunstancias, el Congreso de la República definirá mediante ley las sanciones penales y disciplinarias, tanto de los representantes legales de las entidades a cargo de la prestación del servicio como de las demás personas que contribuyeron a la misma.

Parágrafo $2^{\circ}$. Lo anterior sin perjuicio de la tutela" Con tal disposición se pretende reducir el marco de conflictos relacionados con el acceso al sistema de salud, en tanto, desaparecen diferencias entre el régimen contributivo y el subsidiado, lo cual, constituye un avance en la realización de este derecho fundamental, armonizado con la "concepción integral de la salud, que incluya su promoción, la prevención, la paliación, la atención de la enfermedad y rehabilitación de sus secuelas" a que alude el artículo 15 de la ley 1751 de $201 ._{.}$

No obstante, la misma norma prevé la aparición de conflictos que deben ser resueltos por vía de la acción de tutela, en armonía con los principios constitucionales e internacionales, integradas al ordenamiento jurídico colombiano en razón del bloque de la constitucionalidad.

Adicionalmente, el legislador se reservó la potestad de tipificar hechos punibles y faltas disciplinarias por parte de los prestadores del servicio que lo nieguen, tanto a nivel directivo como ejecutor. Tal disposición complejiza la actividad de los prestadores, quienes además de la responsabilidad civil, estarían sujetos también a las de carácter penal y disciplinaria, si el legislador consecuente con sus propias decisiones establece nuevas tipologías de faltas.

Si bien en el actual Código Penal y Código Único Disciplinario se estatuyen conductas sancionables por omisiones y acciones contra el derecho fundamental a la salud, no existe la responsabilidad directa por negación del servicio, que constituye la novedad que trae el parágrafo 1 del artículo 14 de la Ley 1751 de $2015 .{ }_{2}$

De otra parte, la competencia para establecer las exclusiones explícitas de servicios y tecnologías, conforme a la Ley Estatutaria, le fue asignada, en el plazo "justiciable" de dos años, al Ministerio de Salud y Protección Social y a la "autoridad competente" a través de un procedimiento "técnico-científico, de carácter público, colectivo, participativo y transparente", en la perspectiva de sustituir la supuesta subjetividad del intérprete constitucional, buscando generar en su lugar, prácticas de democracia participativa que involucre a la academia, al profesional de la salud y a los usuarios del sistema, salvaguardando los principios de integralidad e interculturalidad, así lo consagra la Sentencia C-313 de 2014.

De acuerdo con la responsabilidad que le compete al Estado, según el Pacto Internacional de Derechos Económicos, Sociales y Culturales (PIDESC) ${ }_{23^{\prime}}$ la jurisprudencia constitucional impulsará la progresividad para aminorar las exclusiones del servicio de salud. De tal suerte que la ley ordinaria que se profiera será producto de un amplio y participativo debate nacional.

Los seis criterios de exclusión consagrados en el artículo 15 de la Ley Estatutaria son expresos y taxativos en torno al contenido y materias que involucra pero no respecto de su interpretación y aplicación, que no puede ser exegética, sino contextualizada en los casos concretos.

La Corte Constitucional en la Sentencia C-313 de 2014, advirtió que las exclusiones admisibles por mandato de la Ley Estatutaria, únicamente involucran servicios de salud y tecnología, quedando incluidos los restantes elementos de la Observación 14 del Comité de Derechos Económicos Sociales y Culturales, que comprenden "facilidades, establecimientos, bienes (...) y condiciones necesarias para alcanzar el más alto nivel de salud". La Corporación sintetizó en lo pertinente la Observación 14, así:

"(I) Cada Estado debe tener disponibles "un número suficiente de establecimientos, bienes y servicios públicos de salud y centros de atención, así como programas." (II) Los establecimientos, bienes y servicios de salud deben ser accesibles a todos, sin discriminación alguna, en cuatro dimensiones superpuestas: (a) 'no discriminación'; (b) 'accesibilidad física' (c) 'accesibilidad económica' (asequibilidad), y (d) 'acceso a la información'. (III) Los establecimientos, bienes y servicios de salud deberán ser (aceptables) respetuosos de la ética médica y culturalmente apropiados, es 
decir respetuosos de la cultura de las personas, las minorías, los pueblos y las comunidades, a la par que sensibles a los requisitos del género y el ciclo de vida, y deberán estar concebidos para respetar la confidencialidad y mejorar el estado de salud de las personas de que se trate." (IV) Deberán ser también de buena calidad, apropiados desde el punto de vista científico y médico".

Este instrumento internacional, incorporado al ordenamiento jurídico, sirvió como medio de control constitucional en tanto constituyó fuente de creación de la Ley Estatutaria. De donde el criterio de equidad de género y sensibilidad del sistema de salud frente a los asuntos que comporten discriminación de género resulta imperativo.

La aplicación de los criterios a la casuística obliga a garantizar la igualdad de trato entre los seres humanos y a adoptar medidas específicas de la condición femenina que permitan el más alto nivel de protección y goce efectivo del derecho fundamental a la salud por parte de las mujeres y personas con diversidad sexual.

De manera que, la atribución de competencia para excluir explícitamente "servicios o tecnologías" se diluye en tanto que no es posible regular toda la multiplicidad de eventos que pudieran sucederse. La Corte Constitucional en la Sentencia C-313 de $2014,{ }_{1}$ en el análisis de exequibilidad de este aparte normativo trajo a colación varios ejemplos relativos a la exclusión basada en el "propósito cosmético o suntuario" de algunos tratamientos que permiten verificar cómo la exclusión admite excepciones fundadas en la necesidad funcional o de preservación de la dignidad humana.

Entre ellos se tienen las Sentencias T-016 de $2007_{24} \mathrm{y}$ T-561 de $2011_{25}$ en las que estudió los requerimientos de menores, relativos a cirugías; la primera, del lóbulo de una oreja que afectaba su apariencia y la segunda, de reconstrucción de labios vaginales y que las EPS calificaron como cosméticas, negando el servicio, pretendido pese a estar comprometida la salud y dignidad de las niñas.

En las Sentencias T-079 de 2008, ${ }_{26}$ T-392 de 2009 ${ }_{27}$ y T-759 de $2013_{28}$ se analizaron los casos de mujeres quienes, en el primero, se encontraba afectada mentalmente por las quemaduras y llagas causadas por el exceso de piel; en el segundo, padecía similares afecciones luego de practicarse bypass gástrico y en el tercero, la joven requería lifting de brazos y liposucción de espalda y cintura luego de practicarse cirugía bariátrica en la que perdió 40 kilos, lo cual le causó malformaciones cutáneas e infecciones de tipo dermatológico a nivel de senos, abdomen, brazos e ingle, afectando su movilización y dignidad humana. Todas las intervenciones médicas fueron consideradas estéticas y suntuarias y por lo mismo rechazadas por las EPS respectivas, razón por la cual la Corte otorgó las tutelas, ya que en su criterio se trataba de afecciones de salud funcional y dignidad humana, apelando al principio pro homine.

Aludió al frecuente reclamo de suministro de pañales desechables para adultos mayores y personas en condición de discapacidad a quienes se les negó la prestación por considerarlo suntuario, pese a la grave afectación de la dignidad humana, tanto del paciente como de la persona responsable de su cuidado, generalmente, una mujer. En las Sentencias T-841 de 2012, ${ }_{29}$ T-752 de $2012_{30}$ y T-1030 de $2012_{31}$ la Corte concedió el amparo, enfatizando el carácter funcional del servicio. Así mismo, en las Sentencias T-841 de $2012_{27}$ T-591 de $2008_{32}$ y T-212 de $2011_{33}$ ordenó la entrega de sillas de ruedas para salvaguardar la dignidad humana de los tutelantes.

También en materia de salud oral, la Corporación conoció acciones de amparo cuyo estudio se hizo en las Sentencias T-046 de 2012, ${ }_{34}$ T-940 de 2012, T-1276 de 2001, ${ }_{36}$ T-004 de 2008, ${ }_{37}$ T-570 de 2008, T-1271 de $2008_{38}$ y T-402 de 2009,,$_{39}$ manteniendo la línea jurisprudencial de protección integral a la salud, al considerar los problemas orales de carácter funcional y no cosméticos como se había pretendido.

El literal a) del inciso 2 del artículo 15 de la ley 1751 de 2015, mantuvo como criterio de exclusión, los servicios de naturaleza cosmética y suntuaria. Este constituye una categoría sospechosa de discriminación por razón de género porque con frecuencia, como ya se dijo, se asocia lo cosmético con lo femenino y lo suntuario, con lo superfluo, ligado a los estereotipos no masculinos.

Si bien la norma en comento prevé la admisión de esta clase de servicios cuando está de por medio 
"la recuperación o mantenimiento de la capacidad funcional o vital de las personas" se observa la impertinencia de los términos "cosmético" y "suntuario" ya que pierden esta característica si la pretensión final es la recuperación o la preservación de la salud. Por lo tanto, el criterio orientador debió enfatizar en la exclusión de servicios que no estén destinados a recuperar o preservar la salud sin otorgarles calificativos prejuiciosos y discriminatorios, insensibles a la diferencia derivada del sexo y a la diversidad propia de la complejidad humana.

Lo anterior, permite concluir que la competencia para definir exclusiones terminará por trasladarse al intérprete de la norma en caso de conflicto por negación del servicio. Esta situación se torna particular en el ámbito de la salud cuando la finalidad de la Ley Estatutaria es comprometer a los actores del sistema de salud con la aplicación del principio pro persona, mal llamado pro homine, evitando en lo posible la intervención del juez de la salud, juez ordinario o del juez constitucional, estos sí obligados a interpretar, ponderar y aplicar con fundamento en los principios.

Lejos se está de una consciente y real aplicación del principio pro persona mientras los actores del sistema mantengan intereses económicos en la negación del servicio, o, la miopía de género al asociar lo cosmético y suntuario con lo femenino y diverso. De ahí que la racionalidad del intérprete deba soportarse en criterios objetivos, científicos y transparentes que sirvan para encontrar la verdad. Dijo expresamente la Corte en la Sentencia C-313 de 2014:

"Para la Sala, la noción de criterio, en este caso entendida en la acepción de "norma para conocer la verdad", resulta bastante adecuada, pues, (...) se trata de una norma para determinar la exclusión, no de una norma que define, sin más, la exclusión".

Se hace gala de criterios objetivos y científicos en el artículo 16 y 17 de la Ley Estatutaria, ${ }_{2}$ cuando se privilegia la "razonabilidad científica, de acuerdo con el procedimiento que determine la ley" y la autonomía profesional para la definición de diagnósticos y tratamientos ceñidos a la "autorregulación, la ética, la racionalidad y la evidencia científica". Así como también, ganó terreno el imperio de la ciencia sobre las presiones mercantiles en la medida en que prohibió cualquier inducción a la demanda o restricción del servicio bajo el ofrecimiento de bienes o dinero a los trabajadores de la salud por parte de las "empresas farmacéuticas, productoras, distribuidoras o comercializadoras de medicamentos o de insumos, dispositivos y/o equipos médicos o similares".

Se rescata las bondades normativas como instrumentos que pueden servir en procesos de cambio hacia la plena vigencia del derecho a la salud, sin embargo, la ciencia y el derecho deben trabajar mancomunadamente en pro de la humanización del servicio de salud, ya que ni la "objetividad" científica puede arrasar la autonomía individual, ni la concepción de plenitud de derechos puede condicionar el sistema de salud a su arbitrariedad. El principio pro persona equilibra dichas tensiones en beneficio de la dignidad humana.

La inaplicación de dicho principio en sede administrativa continúa siendo susceptible de revisión por las autoridades judiciales. De esta manera, las competencias jurisdiccionales otorgadas a la Superintendencia Nacional de Salud (artículo 41 Ley 1122 de 2007, artículo 22 del Decreto 1018 de 2007, Ley 1438 de 2011) y a los jueces constitucionales se reconocen y mantienen en la Ley Estatutaria y será éste otro ámbito para ejercer el principio pro persona.

Así lo establece de manera clara el parágrafo 2 del artículo 14 al prohibir la negación de servicios “(...) sin perjuicio de la tutela" y de manera ambigua y extraña, el parágrafo 2 del artículo 15 cuando determina que "Sin perjuicio de las acciones de tutela presentadas para proteger directamente el derecho a la salud, la acción de tutela también procederá para garantizar, entre otros, el derecho a la salud contra las providencias proferidas para decidir sobre las demandas de nulidad y otras acciones contencioso administrativas".

La consagración legislativa de la admisibilidad de la acción de tutela contra sentencias en materia de salud es una expresión del carácter protector que revisten los derechos fundamentales, así se manifestó en la Sentencia C-313 de 2014.

El reto para la salud colombiana en el marco de la Ley Estatutaria radica en aminorar las restricciones 
en el disfrute del derecho fundamental a la salud, manejando criterios objetivos y radicando en los diversos actores del sistema la aplicación del principio pro persona.

\section{III. ¿Qué subreglas de la jurisprudencia constitucional garantizan la interpretación conforme al principio pro persona en salud?}

La tendencia hacia la restricción de los derechos en estados con escasez de recursos suele encontrar multiplicidad de justificaciones, llegando inclusive a su desconocimiento. Para evitar tal estado de cosas es necesario recurrir a las subreglas generadas por la jurisprudencia constitucional, que resulta la más avanzada en la defensa del derecho a la salud.

El objetivo de la decantación de las subreglas radica en que ellas puedan ser utilizadas para proceder de manera objetiva cuando se trate de especificar las exclusiones, único evento en que es posible negar el servicio de salud.

El procedimiento a que se hace alusión debe tener en cuenta el principio pro persona por constituirse en una garantía que conduce a la mínima restricción de la exclusión. Desde la Sentencia SU-480 de 1997, ${ }_{40}$ se ponderaron las circunstancias que rodearon a un usuario del servicio de salud que padecía SIDA, a quien se le negó el suministro de medicamentos $\mathrm{y}$ otros servicios, dado que se trataba de una enfermedad de alto costo y que exigía un período mínimo de cotización. Para tutelar, la Corporación consideró la afectación a la vida del paciente, la condición de afiliado al sistema y la intervención del médico tratante, siendo estas unas primeras reglas para conceder el amparo solicitado.

En la Sentencia T-237 de 2003, ${ }_{41}$ analizó la Corte las condiciones requeridas para inaplicar las restricciones normativas para el suministro de medicamentos, fijándolas así:

"a. Que la ausencia del fármaco o procedimiento médico lleve a la amenaza o vulneración de los derechos a la vida o la integridad física del paciente, bien sea porque se pone en riesgo su existencia o se ocasione un deterioro del estado de salud que impida que ésta se desarrolle en condiciones dignas. b. Que no exista dentro del plan obligatorio de salud otro medicamento o tratamiento que supla al excluido con el mismo nivel de efectividad para garantizar el mínimo vital del afiliado o beneficiario.

c. Que el paciente carezca de los recursos económicos suficientes para sufragar el costo del fármaco o procedimiento y carezca de posibilidad alguna de lograr su suministro a través de planes complementarios de salud, medicina prepagada o programas de atención suministrados por algunos empleadores.

d. Que el medicamento o tratamiento excluido del plan obligatorio haya sido ordenado por el médico tratante del afiliado o beneficiario, profesional que debe estar adscrito a la entidad prestadora de salud a la que se solicita el suministro."

De esta manera la Corte, sin hacer alusión expresa, dio aplicación a la hermenéutica mal llamada pro homine, acudiendo: i) "a la norma más amplia", ii) "a la interpretación más extensiva, cuando se trata de reconocer derechos protegidos", iii) "a la norma o a la interpretación más restringida cuando se trata de establecer restricciones permanentes al ejercicio de los derechos o a su suspensión extraordinaria" y iv) preferir la interpretación "que sea más favorable al goce de los derechos", Sentencia T-284 de 2006. ${ }_{42}$

Tiene cabida la interpretación restrictiva que hizo carrera en la Corte Constitucional cuando se está frente a una exclusión, pues diferente resultó el examen de la norma que propiciaba la prestación del servicio de salud requerido con necesidad y que debía prestarse sin dilaciones (literal e) inciso 2 artículo 6 y parágrafo 1 del inciso 2 del artículo 10 del proyecto de ley). En este último evento por tratarse de una norma que reconoce el derecho, la interpretación debía ser extensiva y no restrictiva como quedaba planteada en el texto del proyecto. Ahí la Corte desechó del ordenamiento, el término "requerido con necesidad" y mantuvo la prestación del servicio "sin dilaciones". Esta decisión corresponde al principio pro persona.

Ahora bien, en la Sentencia C-313 de 2014, las subreglas se presentaron así:

“(...)(I)la falta del servicio médico vulnera o amenaza los derechos a la vida y a la integridad personal 
de quien lo requiere; (II) el servicio no puede ser sustituido por otro que se encuentre incluido en el plan obligatorio; (III) el interesado no puede directamente costearlo, ni las sumas que la entidad encargada de garantizar la prestación del servicio se encuentra autorizada legalmente a cobrar, y no puede acceder al servicio por otro plan distinto que lo beneficie; y (IV) el servicio médico ha sido ordenado por un médico adscrito a la entidad encargada de garantizar la prestación del servicio a quien está solicitándolo."

Con estas subreglas la Corte Constitucional garantizó en casos concretos el servicio de salud a todas aquellas personas que recurrieron a la acción de amparo por caracterizar como cosmético o suntuario el servicio solicitado. No obstante, en la ley ordinaria el procedimiento que se adopte para la concreción de las exclusiones deberá asumir estas subreglas a la luz del principio pro persona que requiere impregnarse de la perspectiva de género, desde su propia nominación, para dejar de ser pro homine y entenderse como pro persona. Este lenguaje inclusivo desechará estereotipos que puedan limitar el disfrute del derecho a la salud de mujeres, niñas y población diversa.

La ponderación que dilucide la tensión de derechos será aquella que observando la no discriminación y la dignidad humana restrinja en la menor medida posible, lo que constituye el sentido del principio pro persona.

Estos precedentes constitucionales mantienen su vigencia hasta tanto el Congreso asumiendo sus propios mandatos determine de manera específica las exclusiones a la prestación del servicio de salud y aún, contando con dicha regulación será necesario acudir a las subreglas en tanto se adopten interpretaciones contrarias al principio pro persona.

\section{Conclusiones}

El escenario de la prestación del servicio de salud es un espacio fecundo para la defensa de la equidad de género. Más aún cuando desde el ámbito internacional, Observación 14 del Comité de Derechos Económicos, Sociales y Culturales, se compromete a los estados a incluir la perspectiva de género y la sensibilidad frente a la diversidad en la prestación del servicio de salud. Colombia no está ajena a este reclamo universal. La interpretación y aplicación de la regulación del servicio público de salud por tratarse de un derecho fundamental se debe ceñir al principio pro persona, comprometido con las mínimas restricciones al disfrute efectivo de este derecho.

El peso de la tradición patriarcal es tan fuerte que corporaciones como la Corte Constitucional, que han proferido sentencias a favor de la equidad de género, terminan utilizando lenguaje excluyente o sexista como ocurrió en la Sentencia C-313 de 2014, al analizar el principio pro homine, aceptándolo sin reparo alguno.

Para la búsqueda de las mejores garantías frente a la prestación del servicio de salud, es fundamental recurrir a las subreglas que en casos concretos fijaron las restricciones admisibles, evitando al máximo que dichas medidas vulneraran el acceso al derecho a la salud. Aspectos como el riesgo a la afectación de la vida y la dignidad del ser humano, la ausencia de alternativas terapéuticas, la carencia de recursos económicos y la prescripción médica son variables que jamás podrán dejar de considerarse cuando se pretenda negar un servicio de salud.

Pese a que el lenguaje suele distanciar hombres, mujeres y población diversa, la salud y la enfermedad comunica a todas las personas por igual. Este escrito constituye una invitación para que el sector salud se sensibilice frente a la igualdad de género y diversidad en coherencia con el respeto a la dignidad humana, sea cual fuere la disciplina de su regulación.

\section{Referencias}

1. Colombia. Corte Constitucional. Bogotá D.C. M.P. Gabriel Eduardo Mendoza Martelo. Sentencia C-313 (May. 29, 2014).

2. Colombia. Congreso de la República. Bogotá D.C. Ley Estatutaria 1751 de 2015. Por medio de la cual se regula el derecho fundamental a la salud y se dictan otras disposiciones. (Feb. 16, 2015).

3. Salvioli F. Un análisis desde el principio pro persona, sobre el valor jurídico de las decisiones de la Comisión Interamericana de derechos humanos. En: En defensa de la Constitución: libro homenaje a Germán Bidart Campos. Buenos Aires: Ediar; 2003.

4. Vivanco A. Disposición sobre la vida humana y principios constitucionales: análisis del caso chileno; 2013 [citado 19 Jul 2015]. Disponible en: http://ruc. 
udc.es/bitstream/2183/10322/2/VivancoMartinez_ Angela_TD_2013.pdf

5. Castaño R. Ley Estatutaria en Salud: del espejismo del derecho ilimitado a la realidad de los recursos finitos. 2013 [citado 15 Jun 2015]. Disponible en: http://franciscoazuero.blogspot.com/2013/07/leyestatutaria-en-salud-del-espejismo.html

6. Ariza G. De inapelable a intolerable. Bogotá D.C: Universidad Nacional de Colombia; 2012.

7. Mepham D. Un desarrollo en consonancia con los derechos humanos. La integración de los derechos en una agenda pos t-2015. 2015 [citado 20 Jun 2015]. Disponible en: http://www.hrw.org/sites/default/ files/reports/wr2014sp_web.pdf

8. Cortés J. Ley Estatutaria de Salud. Bogotá D.C: Legis; 2015.

9. López D. El derecho de los jueces. Bogotá D.C: Legis; 2006.

10. Naciones Unidas. Declaración Universal de Derecho Humanos. 1948 [citado 04 Jun 2015]. Disponible en: http://www.un.org/es/documents/udhr/

11. Naciones Unidas. CEDAW. 1979 [citado 10 Jun 2015]. Disponible en: http://www.un.org/womenwatch/ daw/cedaw/text/sconvention.htm

12. Díaz D. La visibilización de los derechos humanos de la comunidad LGBT en la ONU y su implicación para América Latina. [citado 13 Jun 2015]. Disponible en: http://soda.ustadistancia.edu.co/enlinea/congreso/ MemoriasXICongreso/Ponencia\%20David\%20 DIAZ\%20BEJARANO.pdf

13. Colombia. Asamblea Nacional Constituyente. Bogotá D.C. Constitución Política de Colombia. (Jul. 20, 1991).

14. Colombia. Corte Constitucional. Bogotá D.C. M.P. Luis Ernesto Vargas Silva. Sentencia T-570 (Ago. 26, 2013).

15. MedellínX. Principio pro persona. Comisión de Derechos Humanos del Distrito Federal. México D.F: D. R; 2013.

16. Colombia. Corte Constitucional. Bogotá D.C. M.P. Humberto Sierra Porto. Sentencia C-804 (Sep. 26, 2006).

17. Organización de los Estados Americanos. Convención Americana sobre Derechos Humanos. 1948 [citado 04 Jun 2015]. Disponible en: http://www.oas.org/dil/ esp/tratados_B-32_Convencion_Americana_sobre_ Derechos_Humanos.htm

18. Corte IDH, Opinión Consultiva OC-5/85, "La colegiación obligatoria de periodistas (artículos 13 y 29, Convención Americana sobre Derechos Humanos)", del 13 de noviembre de 1985, Serie A, no 5, párrafo 46.

19. Aguirre J. La interpretación de la Convención Americana sobre Derechos [citado 6 Sep 2014] Disponible en: http://www.corteidh.or.cr/tablas/R22853.pdf

20. Colombia. Consejo de Estado, Bogotá D.C. C.P. Marco Antonio Velilla Moreno, rad.: 76001-23-33-000-201300967-01. Sentencia de habeas corpus (Sep. 26, 2013).
21. Naciones Unidas. Aplicación del Pacto Internacional de los Derechos Económicos, Sociales y Culturales, Observación general 14, El derecho al disfrute del más alto nivel posible de salud (artículo 12 del Pacto Internacional de Derechos Económicos, Sociales y Culturales). 2000 [citado 10 Jun 2015]. Disponible en: http://www1.umn. edu/humanrts/gencomm/epcomm14s.htm

22. Castaño R. Medicina, ética y reformas a la salud. Bogotá D.C: Ecoe ediciones; 2000.

23. Naciones Unidas. PIDESC. 1966 [citado 10 Jun 2015]. Disponible en: http://www.ohchr.org/SP/ ProfessionalInterest/Pages/CESCR.aspx

24. Colombia. Corte Constitucional. Bogotá D.C. M.P. Humberto Sierra Porto. Sentencia T-016 (Ene. 22, 2007).

25. Colombia. Corte Constitucional. Bogotá D.C. M.P. Luis Ernesto Vargas Silva. Sentencia T-561 (Jul. 18, 2011).

26. Colombia. Corte Constitucional. Bogotá D.C. M.P. Rodrigo Escobar Gil. Sentencia T-079 (Ene. 31, 2008).

27. Colombia. Corte Constitucional. Bogotá D.C. M.P. Humberto Sierra Porto. Sentencia T-392 (May. 28, 2009).

28. Colombia. Corte Constitucional. Bogotá D.C. M.P. Nilson Pinilla Pinilla. Sentencia T-759 (Oct. 31, 2013).

29. Colombia. Corte Constitucional. Bogotá D.C. M.P. María Victoria Calle Correa. Sentencia T-841 (Oct. 23, 2012).

30. Colombia. Corte Constitucional. Bogotá D.C. M.P. María Victoria Calle Correa. Sentencia T-752 (Sep. 26, 2012).

31. Colombia. Corte Constitucional. Bogotá D.C. M.P. Alexei Julio Estrada. Sentencia T-1030 (Dic. 03, 2012).

32. Colombia. Corte Constitucional. Bogotá D.C. M.P. Jaime Córdoba Triviño. Sentencia T-591 (Jun. 19, 2008).

33. Colombia. Corte Constitucional. Bogotá D.C. M.P. Juan Carlos Henao Pérez. Sentencia T-212 (Mar. 28, 2011).

34. Colombia. Corte Constitucional. Bogotá D.C. M.P. Juan Carlos Henao Pérez. Sentencia T- 046 (Feb. 07, 2012).

35. Colombia. Corte Constitucional. Bogotá D.C. M.P. Nilson Pinilla Pinilla. Sentencia T- 940 (Nov. 13, 2012).

36. Colombia. Corte Constitucional. Bogotá D.C. M.P. Alvaro Tafur Galvis. Sentencia T-1276 (Nov. 30, 2001).

37. Colombia. Corte Constitucional. Bogotá D.C. M.P. Mauricio González Cuervo. Sentencia T-004 (Ene. 15, 2008).

38. Colombia. Corte Constitucional. Bogotá D.C. M.P. Mauricio González Cuervo. Sentencia T-1271 (Dic. 18, 2008).

39. Colombia. Corte Constitucional. Bogotá D.C. M.P. Jorge Ignacio Pretelt Chaljub. Sentencia T-402 (Jun. 04, 2009).

40. Colombia. Corte Constitucional. Bogotá D.C. M.P. Alejandro Martínez Caballero. Sentencia SU-480 (Sep. 25, 1997).

41. Colombia. Corte Constitucional. Bogotá D.C. M.P. Jaime Córdoba Triviño. Sentencia T-237 (Mar. 20, 2003).

42. Colombia. Corte Constitucional. Bogotá D.C. M.P. Clara Inés Vargas Hernández. Sentencia T-284 (Abr. 05, 2006). 